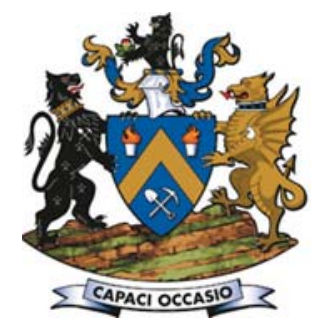

\title{
Market implications for technology acquisition modes in the South African ferrochrome context
}

\author{
by E. van der Lingen and $A$. Paton
}

\section{Synopsis}

The South African ferrochrome industry has been faced with various challenges during the past few years, such as influences from the market, manpower strikes, China's control over the demand for both ferrochrome and chrome ore from South Africa, and electricity supply constraints, placing increased pressure on the local industry to improve output in order to remain globally competitive. The year 2016 brought a dramatic change in the local ferrochrome industry, being marked by higher chrome ore prices and the takeover of some idle smelters.

This study investigates the methods of technology acquisition used in various parts of the ferrochrome smelter value chain throughout a business cycle, and whether there is a preference for a specific acquisition in an explicit part of the value chain. The study also considers whether companies prefer to partner with local or global institutions for collaborative development, and the methods used by companies to protect their technologies.

Keywords

Technology acquisition modes, ferrochrome, value chain, business cycle.

\section{Introduction}

South Africa holds the world's largest chrome ore reserves and was the world's largest producer of ferrochrome until 2012, when China became the leading ferrochromeproducing country. South Africa's chrome ore (chromite) supply into the Chinese market has risen significantly from $36 \%$ of China's total chrome ore imports in 2010 to more than $70 \%$ in 2016 (Fowkes, 2014; Creamer, 2017). China controls the demand for both ferrochrome and chrome ore from South Africa (Fowkes, 2014). China's high import rate of chrome ore has resulted in ferrochrome prices being driven down and a depressed ferrochrome market. The South African industry meets the chrome ore demands but loses out on ferrochrome beneficiation.

Furthermore, the local ferrochrome industry has been threatened with the overall poor competitiveness over the past few years, resulting in four of the eight producers ceasing operations at the beginning of 2016.

Challenges experienced by the producers, some of which are directly linked to production costs, include influences from the market, productivity that was affected by wildcat strikes, China's control over the demand for both ferrochrome and chrome ore, and electricity supply issues (Fowkes, 2014, 2013; Biermann, Cromarty, and Dawson, 2012). Ferrochrome production is energy-intensive and South African producers have faced higher electricity costs, electricity supply complications, and a weaker currency exchange rate since 2009.

Ferrochrome is an iron-chromium alloy that contains between $50 \%$ and $70 \%$ chromium by weight. Chromium is one of the fundamental metals used in modern steelmaking and superalloys due to its excellent corrosion resistance, and it is regarded as a commodity of critical and strategic importance (Murthy, Tripathy, and Kumar, 2011). China is currently the world's top producer of ferrochrome, despite its lack of significant chrome resources, as well as the world's leading stainless steel producer (US Geological Survey, 2017). Global stainless steel production rose by more than $8 \%$ in 2016, resulting in an increase in chrome ore and ferrochrome demand (see Figure 1). The year 2016 brought a dramatic change in the local ferrochrome industry. It was marked by idle smelters in the beginning of that year, take-overs in the industry, and chrome ore prices reaching the highest levels since the global economic downturn in the third quarter of 2016.

The purpose of this study is to link the value chain and business cycle to the choice of technology acquisition mode (TAM) in the South African ferrochrome industry. Although this area has been studied extensively in the electronics industry, there is a gap in the body of knowledge in the mining industry. Previous research has been fragmented, with only a few parameters being studied at a specific time for

* Department of Engineering and Technology Management, University of Pretoria, South Africa. (c) The Southern African Institute of Mining and Metallurgy, 2018. ISSN 2225-6253. Paper received Aug. 2017; revised paper received Jun. 2018. 


\section{Market implications for technology acquisition modes in the South African ferrochrome context}

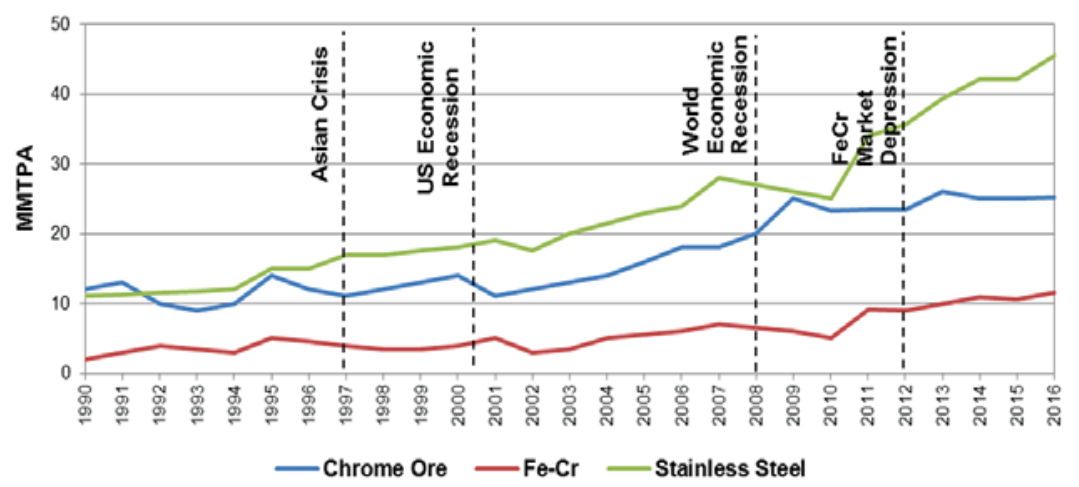

Figure 1-Global production of stainless steel, chrome ore, and ferrochrome (FeCr) for the period 1990-2016 (Kleynhans, 2011; Richard, 2015; International Ferro Metals (IFM), 2013; CRU Group, 2017)

appropriate modes. The theory does not link these aspects together, but it is important to understand the mining context because of the increasing pressures to improve management outputs to attain global competitiveness.

\section{Literature study}

\section{Technology acquisition modes}

Technology acquisition strategy is seen as the process of selecting acquisition modes using technical and non-technical capabilities and integration of the selected technology into the value chain (Burgelman, Christensen, and Wheelwright, 2004; Cho and Pyung-Il, 2000). According to Lundquist (1999), the technology developed must be a value creator that meets the organization's needs. There are various types of technology acquisition mode (TAMs), but in-house development and technology purchasing are the umbrella terms used to describe a whole range. A third mode that is considered in this study, collaborative development, requires the involvement of internal and external capabilities.

In-house development is defined as the execution of development as a task in the organization's existing structures, namely its research and development (R\&D) department (Cho and Pyung-Il, 2000). The advantages of inhouse development are as follows (Schlorke, 2011):

$>$ Tacit knowledge is gained

> The technology that is developed becomes the property of the developer

> Competitive advantage becomes exclusive to the developer

> There is an opportunity to increase revenue by the sale or licensing of the developed technology. follows:

The disadvantages of in-house development are as

> Long development times

> Increased development costs

> Potential disruption of production

- The possible lack of internal resources to complete the development.

Technology purchasing is broadly defined as acquiring technologies by contracts, licensing, or simply purchasing from a provider. This mode neither utilizes internal capabilities nor requires any technical collaboration (Cho and Pyung-Il, 2000). The advantages of technology purchasing are potential cost reduction, lower risks, and shorter implementation times (Schlorke, 2011). However, purchasing of technology does not guarantee a competitive advantage and there is usually no valuable exchange of tacit knowledge in the process. Sourcing technologies externally may reduce the need to sustain internal technical capabilities and may also speed up the implementation of products and processes (Tsai and Wang, 2008).

Collaborative development can be defined as the complementing of internal resources in the innovation process, enhancing both the innovation input and output measured by the realization of innovations (Becker and Dietz, 2004).

Cho and Pyung-Il (2000) used the integrated framework set out in Figure 2 to investigate how companies acquire the necessary technology using an integrated approach on the basis of previous studies.

Cho and Pyung-Il (2000) stated that a company's historical pattern of choice was the most significant factor in discriminating between the modes. Based on an evolutionary economics perspective, routines are more likely to affect how firms perceive changes in the environment, their possible responses, and the choices they make. The environment and framework represent the dynamic influences that any management system must be able to accommodate to determine the best acquisition modes.

Kurokawa (1997) investigated variables that affect technology acquisition decisions. The variables included the influence of the time-to-revenue and time-versus-cost relationships, as well as intervening variables. The most relevant variables to manufacturing operations are the following:

\section{Variables that influence the time-to-revenue relationship}

$>$ The degree of competition-An increase in competitors stimulates external acquisitions because the increased competitive pressures further diminish the potential revenue of technology laggards.

> The degree of protection - If new products require a high degree of protection of technical know-how through patents, copyrights, or trade secrets, in-house $R \& D$ is preferred over technology purchasing. 


\section{Market implications for technology acquisition modes in the South African ferrochrome context}

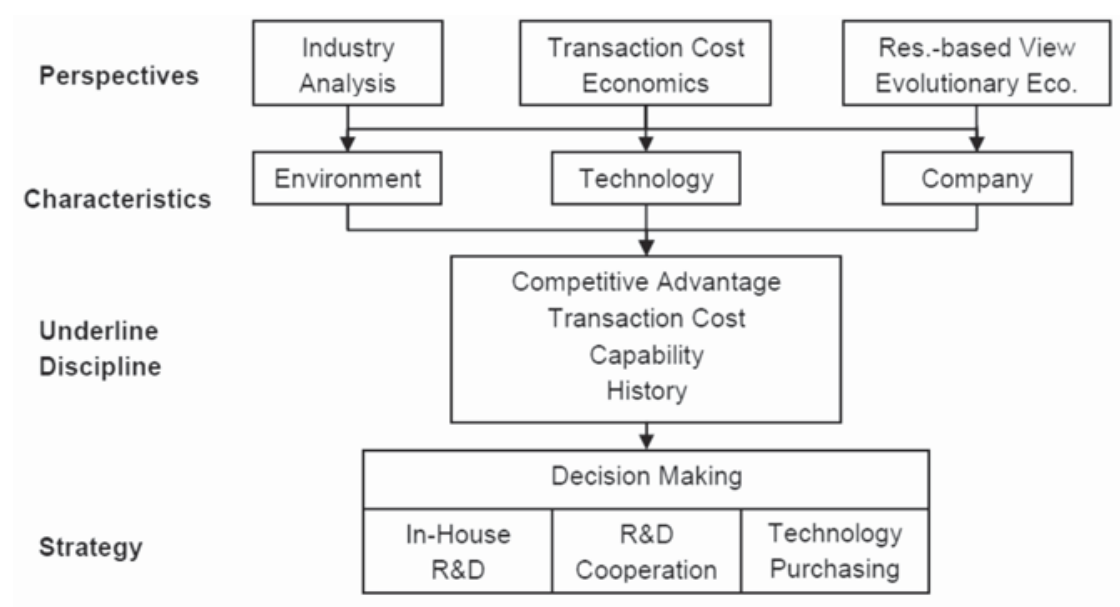

Figure 2-The adapted integrated framework for technology acquisition modes (Cho and Pyung-II, 2000)

Variables that affect the time-versus-cost relationship

> Relatedness of the technology-If the company's development focus is related to its core technology, its own personnel and resources are utilized. In-house development becomes cheaper and less timeconsuming than purchasing. The opposite is true if the development focus is on non-core technologies if inhouse development is used.

\section{Intervening variables}

> History - A firm is more likely to select the same TAM that has been used in the past.

$>R \& D$ capability-The more advanced the in-house development capability of a company, the more it will utilize the capabilities available for $\mathrm{R} \& \mathrm{D}$, and the more likely it is to purchase technology to advance its inhouse $R \& D$ capabilities.

Simatupang (2006) found that few studies have been conducted into the practices and characteristics of the technology acquisition process for companies in developing countries. Most of the current studies were conducted in the developed nations, such as the USA, UK, and Japan, where competitiveness is driven by technology development. Schlorke (2011) provides the most recent study linking technology acquisition and product development processes in the South African electronics industry. The studies conducted in the different countries all evaluated the electronics industry and focused on product development and programme management, unlike the ferrochrome industry, which focuses on production capacity and process efficiency.

\section{Business cycle}

Industry-specific business cycles are characterized by four phases: boom, recession, depression, and recovery. Figure 3 depicts the key activities and events during the four different phases of the business cycle in the mining industry as related specifically to smelting operations. Business cycles are consequences of either a large sole cause or smaller events in the market, such as the sub-prime crisis (2009 recession) or capital projects (Roberts, 2009). The end consumption of the mining industry's products depends on the level of activity in industries such as construction and automotive manufacturing. Inventories tend to grow during recessions and shrink during booms, a fluctuation based on demand which affects market price (Vinell, 1997). There has been a consistent growth in consumer demand, but the mining industry's capacity has often exceeded that demand in the past, leading to cyclicality (Sheridan, 1997).

During the boom periods, investment for increased capacity in anticipation of future growth based on current assumptions tends to be delayed (Alajoutsijärvi et al., 2012). In 2006, the mining industry faced a boom period driven by the high rate of infrastructure construction in China. China's huge demand for metals created a market situation that encouraged the exploitation of any reserve (Alajoutsijärvi et al., 2012).

The sub-prime crisis put a strain on many mining companies. When prices are lower, outputs are limited and capital projects postponed. Expansions and new projects in the mining industry depend strongly on commodity prices, as they influence the volatility of the project cash flows. One of the main purposes of predictive models for commodities is to aid the appraisal process and justify risk in relation to returns. Mine or smelter expansions require a sound knowledge of the mine life, cost of production (affected by the selected technology), a view on the commodity price for the life of the project, and an understanding of the specific commodity demand projection (Shafiee and Topal, 2010; Crowson, 2001).

Inventory shortages result in inflated markets and can indicate an imminent economic recession. The potential recovery from this recession is marked by the introduction of new buyers that gradually grow demand (Alajoutsijärvi et al., 2012). Individual investors, pension fund portfolio managers, and hedge funds are examples of buyers who create a demand for mining products. Resource-rich countries that generate large tax revenues and royalties tend to have governments with a strong influence over the demand for their own mining products (Jerrett and Cuddington, 2008).

This section provides background to the different phases within a business cycle. Within this study the business cycle phases will be linked to the selection of TAM in the South African ferrochrome industry. 


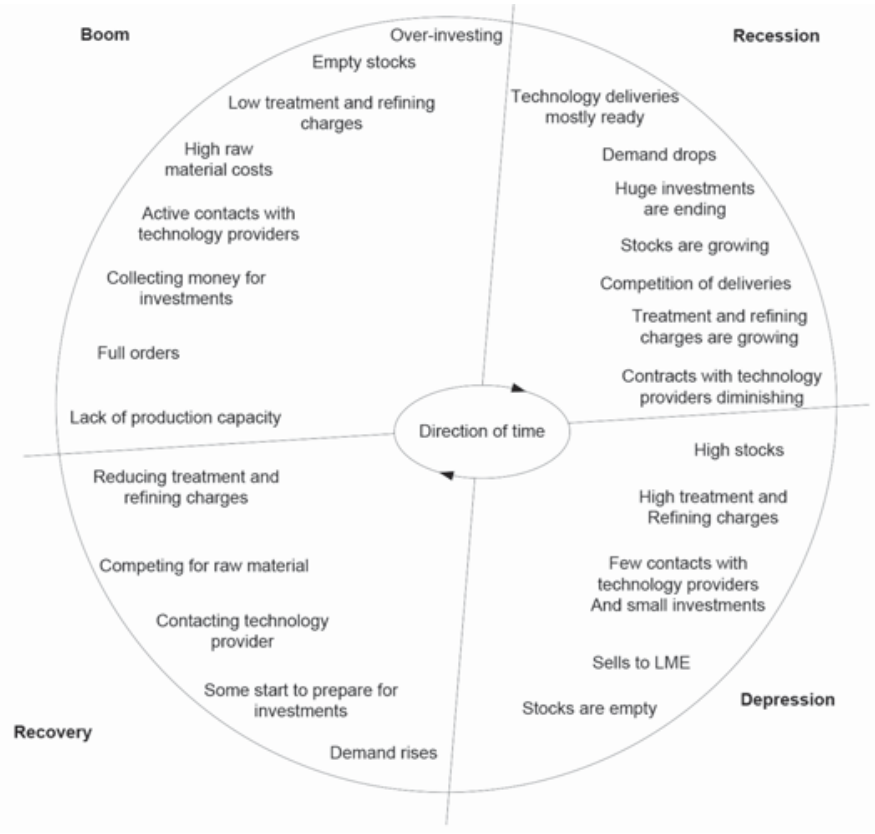

Figure 3-The key activities and events during different phases of the business cycle in the mining industry pertaining to smelters (Alajoutsijärvi et al., 2012)

\section{Conceptual framework and research objectives}

Ford (1988) states that it is important to evaluate the company's level of knowledge concerning its own and emerging technologies. This evaluation must be understood across the value chain, from upstream development to downstream activities of marketing and aftermarket services. The conceptual framework in which to investigate relationships in the ferrochrome smelting industry includes the variables, TAMs, and the smelter product value chain areas (VCAs). A longitudinal study was conducted in order to assess the changes of these modes throughout a business cycle. The linking of TAMs to the VCAs and the business cycle is depicted in the framework in Figure 4.

The main objective of the current study is to determine whether the methods of technology acquisition used in various parts of the ferrochrome smelter value chain have an impact on the company throughout the business cycle. Other objectives include determining whether there is a preference for a specific acquisition in an explicit part of the value chain, whether companies prefer to partner with local or global institutions for collaborative development, and methods used by companies to protect their technologies.

The following research questions were investigated:

1. Do TAMs used by the ferrochrome industry change during different phases of the business cycle?

2. Will a greater focus on specific key and support process areas result in an increased preference for inhouse development?

3. Will the departments responsible for technological innovation and selecting the TAMs in the ferrochrome industry differ between private and public entities?

4. Does the South African ferrochrome industry approach local institutions, such as the science councils, universities, and consultants, rather than global institutions when conducting collaborative development?
5. Does the ferrochrome industry use protection methods to safeguard its distinctive technologies?

\section{Research methodology}

To address the research objectives, the research design combines qualitative and quantitative analysis methods of non-experimental research (no variables are controlled). The qualitative methods consisted of electronic surveys and follow-up telephonic interviews with the management of the ferrochrome producers. The research questions asked in the survey are related to the described conceptual framework and are designed to answer the research problem by avoiding bias. The quantitative methods included the assessment of

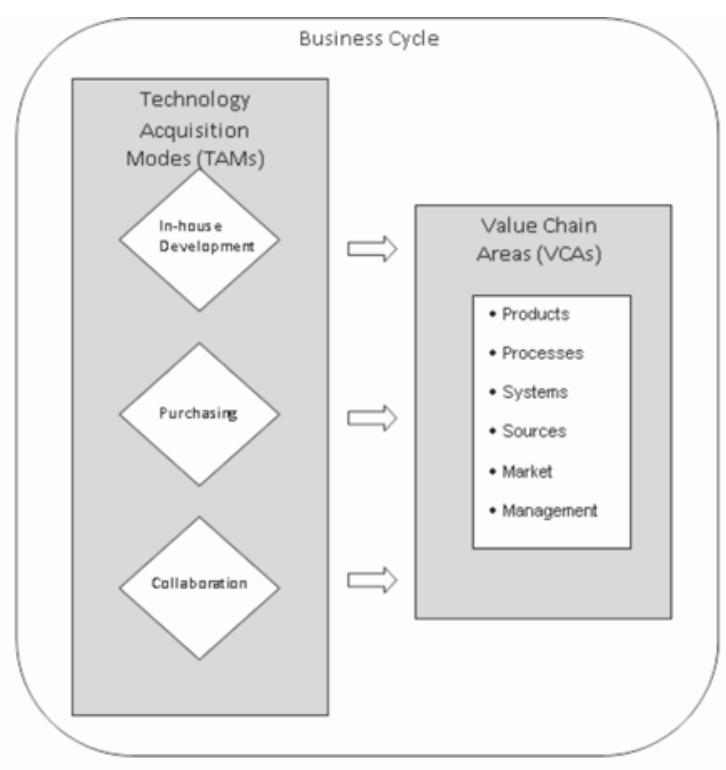

Figure 4-Integrated conceptual framework 


\section{Market implications for technology acquisition modes in the South African ferrochrome context}

open-source data, such as production figures and high-level market share values published in the annual reports of the various ferrochrome producers, as well as government reports.

There are 14 ferrochrome smelters in South Africa. They were operated by eight different companies at the beginning of 2016 (see Table I). Some three-quarters of the companies were publicly listed. Although quantitative data was not available for the privately owned companies, the correlations observed in the study provide a good indication of the impacts of the market conditions in the industry itself.

Responses to the surveys were received from managers from all eight companies (26 respondents) in the population. The respective companies' responses are summarized by assigning weights to the position and experience of the respondent. The population is stratified into publicly listed and privately owned companies because of the limited quantitative data available for the private companies.

\section{Results and discussion}

\section{Do TAMs used by the ferrochrome industry change during different phases of the business cycle?}

Table II and Figure 5 show the influence of different phases of the business cycle on TAMs. Technology purchasing was the predominant acquisition mode during the boom phase. The overall trend of diminishing technology purchasing as the business cycle changes from boom to recession and then depression is confirmed. As soon as the recession hits, investment shrinks, which leads to a focus on internal capabilities driving technology development. The preference for in-house development appears to be independent of inhouse capabilities, but depends rather on the business cycle phase. Collaborative development is preferred over purchasing only during a depression. This means that

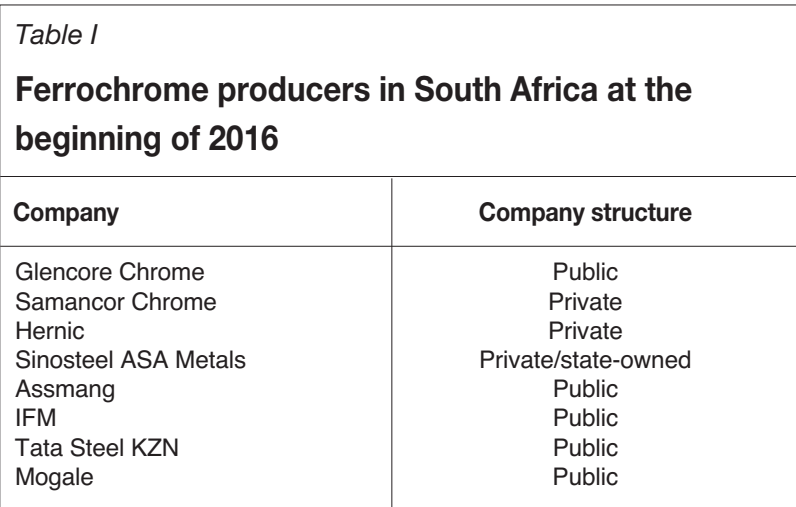

consultants and institutions should have more opportunities during this time in the context of ferrochrome smelters.

There are gaps in the body of knowledge regarding the actual impact of the phases in a business cycle on the preferred TAM. Many theories describe various factors that affect the mode selection (Cho and Pyung-Il, 2000;

Kurokawa, 1997; Schlorke, 2011), but none have highlighted the business cycle, which is important to a commodity producer, such as the ferrochrome industry, as this is what drives demand for the product. The ferrochrome industry is vulnerable to many factors and requires consistent adaptation to changes. Difficulties in sustaining technology management strategies are particularly experienced in developed countries.

The study also investigated whether there is a difference between the TAMs that private and public companies select during the depression phase (see Figure 6). Public companies use mainly in-house development and private companies use collaboration and purchasing.

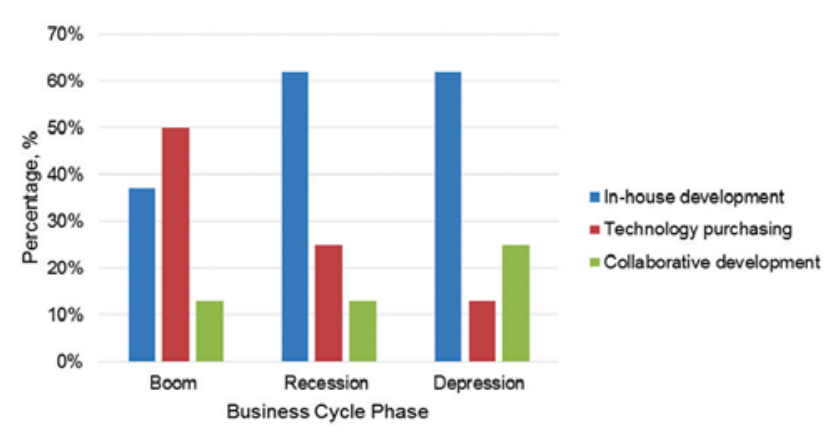

Figure 5-TAM preferences in different phases of the business cycle

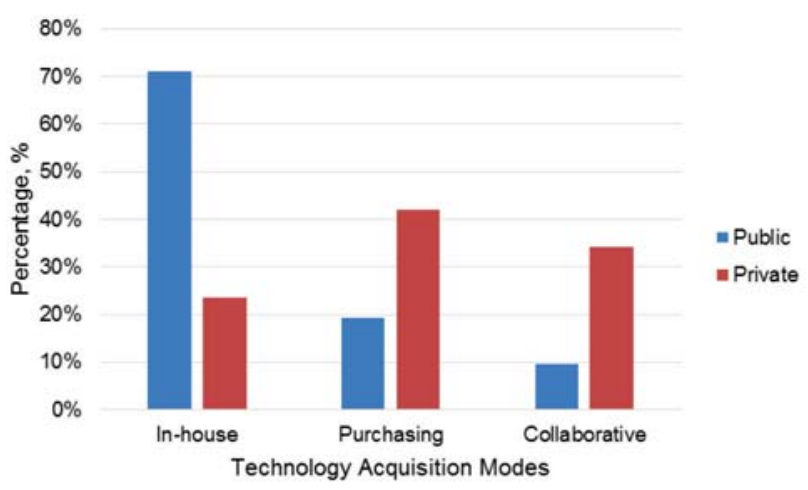

Figure 6-Preferred TAMs for public and private ferrochrome companies during the depression phase

Table II

Phases of the business cycle and modes of technology acquisition

\begin{tabular}{|l|c|c|c|}
\hline \multirow{2}{*}{ Phases of business cycle } & \multicolumn{3}{|c|}{ Acquisition mode } \\
\cline { 2 - 4 } & In-house development & Technology purchasing & Collaborative development \\
\hline Boom (2004-2007) & $37 \%$ & $50 \%$ & $13 \%$ \\
Recession (2008-2009) & $62 \%$ & $25 \%$ & $13 \%$ \\
Depression (2010-2016) & $62 \%$ & $13 \%$ & $100 \%$ \\
\hline
\end{tabular}




\section{Market implications for technology acquisition modes in the South African ferrochrome context}

> Technology purchasing was the predominant acquisition mode during the boom period, with inhouse development dominating during the recession and depression phases. Collaborative development is preferred over purchasing only during a depression phase.

\section{Will greater focus on specific key and support areas result in an increased preference for in-house development?}

Table III shows that technologies are developed mostly for key area processes and support area systems, followed by management innovation. Furthermore, for key area processes and support area systems, the preferred TAM is technology purchasing. Similar results were obtained for the TAMs inhouse development and collaborative development for the key and support focus areas. On the other hand, the preferred TAMs for management innovations are in-house development and collaborative development, with the lowest score being that of technology purchasing.

Lastly, the value chain is well understood in the industry and each area of the value chain is managed accordingly. It is clear that these relationships have not been investigated in an integrated way in the past because it is not clear who manages technology development in a company. It is unlikely that a software engineer manages technological innovation in the key process area or that production departments manage innovation in the finance department. For these reasons, and because the body of knowledge is still very vague, it is not deemed pragmatic to address the relationship between TAMs and the value chain in an integrated framework.

> The focus areas of the investigated value chain showed that technology purchasing was the preferred TAM for both the key and support focus areas, and was preferred above in-house development, as anticipated. In-house development is one of the most important TAMs for management innovation, but cannot be singled out.

Will the responsible departments for technological innovation and selecting the TAMs in the ferrochrome industry differ between private and public entities?

The management of each ferrochrome producer functions in a different organogram, which means that technology management and thus TAM selection is performed by specific functional groups in the business. Table IV shows the distribution among departments that are responsible for technological innovation in the South African ferrochrome industry during a depression period. The distribution of innovation responsibility is relatively evenly spread among the departments in the industry as a whole, except for lower values for the technology and capital projects departments. In the private sector, a slightly higher assignment resulted in the business integration systems (BIS) department being assigned responsibility for developing technologies, whereas a slightly lower assignment was found for the technology department (Figure 7). For public companies, the distribution was relatively equal among the different departments with technology, maintenance, and production departments scoring slightly higher.

The primary focus of the responsible departments is not restricted to a single dimension, as shown in the results in Figure 8 . The focus of private and public companies is mainly on increased productivity, profit, and improved quality. However, public companies also reported some focus on the job satisfaction of staff members and increased market share.

> The departments chiefly responsible for technological innovation differ between the public and private sectors, with the BIS departments being mainly responsible in the private sector and the maintenance and production departments being responsible in the public sector.

\section{Table IV \\ The departments responsible for technology management and TAMs in both public and private companies}

\begin{tabular}{|l|c|}
\hline Responsible department & Average distribution \\
\hline Technology department & $13 \%$ \\
Capital projects & $13 \%$ \\
Maintenance & $20 \%$ \\
Controls and instrumentation & $17 \%$ \\
Production & $20 \%$ \\
BIS & $17 \%$ \\
\hline
\end{tabular}

\section{Table III}

Focus areas of the value chain and modes of technology acquisition

\begin{tabular}{|c|c|c|c|c|c|}
\hline \multicolumn{3}{|l|}{ Focus area } & \multicolumn{3}{|c|}{ Acquisition mode } \\
\hline & & & In-house development & Technology purchasing & Collaborative development \\
\hline \multirow[t]{3}{*}{ Key } & Products & $18 \%$ & $21 \%$ & $12 \%$ & $22 \%$ \\
\hline & Processes & $32 \%$ & $33 \%$ & $41 \%$ & $30 \%$ \\
\hline & Sources & - & - & - & $4 \%$ \\
\hline Support & Systems & $27 \%$ & $29 \%$ & $41 \%$ & $30 \%$ \\
\hline \multirow[t]{2}{*}{ Management } & Market & - & $4 \%$ & - & - \\
\hline & Management & $23 \%$ & $13 \%$ & $6 \%$ & $13 \%$ \\
\hline \multicolumn{2}{|l|}{ Total } & $100 \%$ & $100 \%$ & $100 \%$ & $100 \%$ \\
\hline
\end{tabular}




\section{Market implications for technology acquisition modes in the South African ferrochrome context}

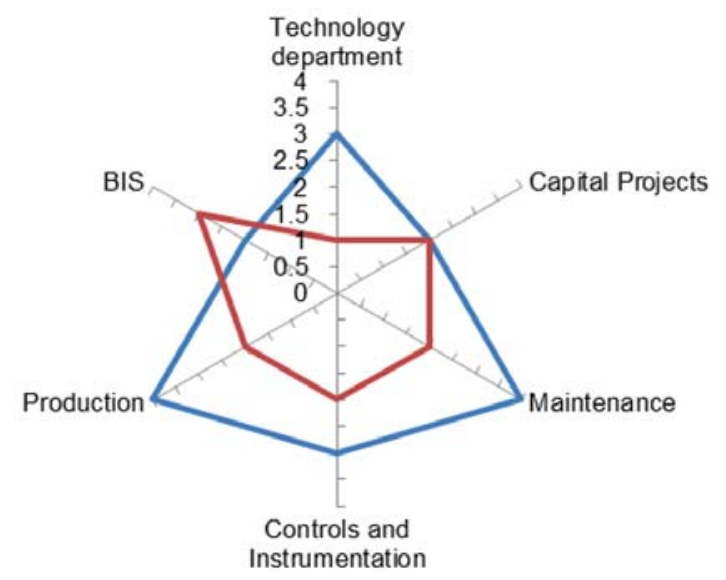

Figure 7-The departments responsible for technological innovation in a company

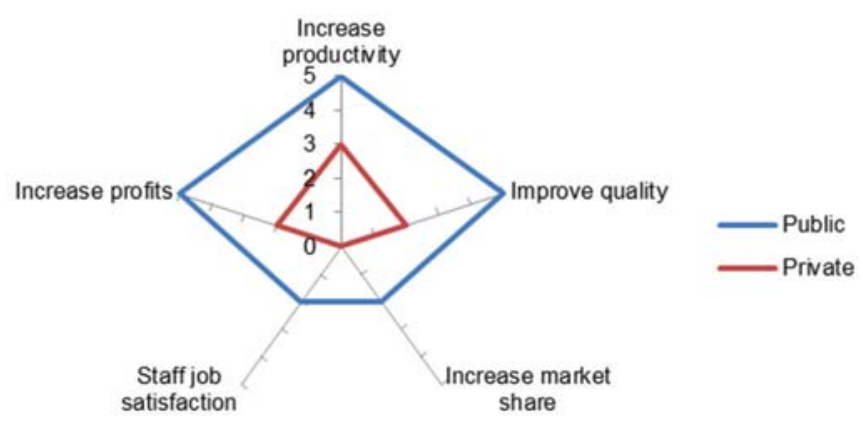

Figure 8-The focus of the department responsible for technological innovation in the organization

Does the South African ferrochrome industry approach local institutions, such as science councils, universities, and consultants, rather than global institutions when conducting collaborative development?

The South African ferrochrome industry is inclined to collaborate with local institutions (see Figure 9). The majority of the collaborative work is conducted with the South African science councils, followed by consultants, and then universities. As South Africa is a major producer of FeCr, the local organizations have significant know-how in the field and the country is a leading user of the best available smelting technology. Global institutions constitute less than $20 \%$ of the partnerships in collaborative development.

> The South African ferrochrome industry prefers local institutions for collaborative development.

\section{Does the ferrochrome industry use protection} methods to safeguard its distinctive technologies? The South African ferrochrome industry is in general very protective of its technologies and uses various methods to protect them, as shown in Figure 10. Confidentiality agreements, followed by retaining know-how in-house, appeared to be the foremost means of protecting technologies. Legal protection methods, such as patenting and licensing, are also often employed in this sector. None of the companies use trademarks as a protection mode.
- The South African ferrochrome industry often uses protection methods, such as confidentiality agreements, retaining know-how in-house, patents, and licences.

\section{Conclusions}

The study found that the TAM used by the ferrochrome industry changes during the different periods in a business cycle. Technology purchasing was the predominant acquisition mode during the boom period. As the cycle moved from a boom to a recession and then to a depression,

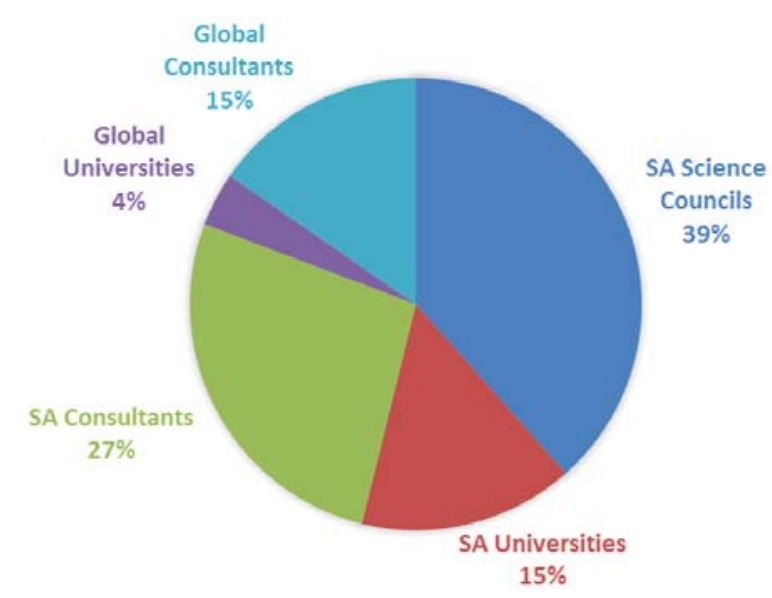

Figure 9-Preferred partners for collaborative development 


\section{Market implications for technology acquisition modes in the South African ferrochrome context}

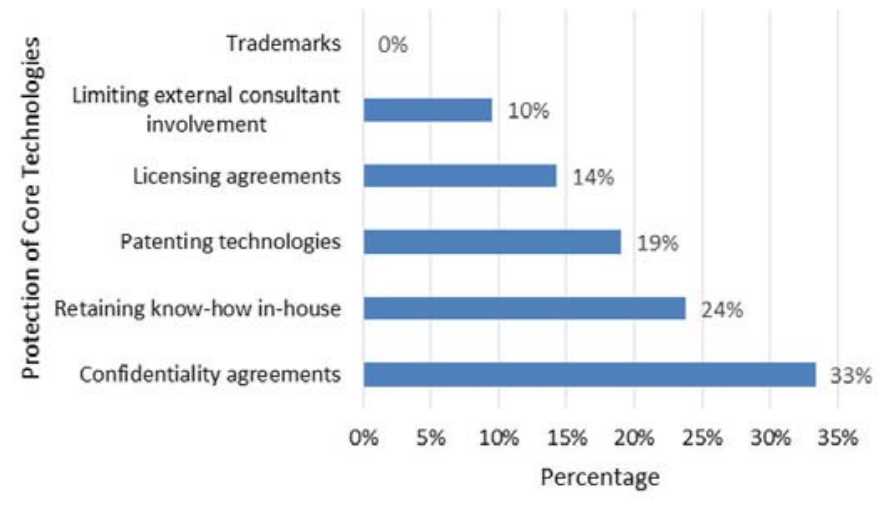

Figure 10-The protection methods used by the ferrochrome industry

technology purchasing became less dominant and in-house development became the preferred TAM. Collaborative development is preferred over purchasing only during a depression.

Technology purchasing was the preferred TAM for both the key and support focus areas. The departments that are mainly responsible for technological innovation differ between the public and private sectors, with the BIS departments being mainly responsible in the private sector, and the maintenance and production departments in the public sector.

The majority of collaborative development projects are conducted with South Africa science councils, followed by consultants, and then universities. Furthermore, the South African ferrochrome industry often uses protection methods, such as confidentiality agreements, retaining know-how inhouse, patents, and licences.

Since the original investigation, there has been a significant reconsolidation of the local ferrochrome industry. This occurred mainly due to increased production costs that were no longer sustainable (based on follow-up interviews with personnel).

\section{References}

Alajoutsijärvi, K., Mainela, T., Ulkuniemi, P., and Montell, E. 2012. Dynamic effects of business cycles on business relationships. Management Decision, vol. 50. pp. 291-304.

BECKER, W. AND DiETZ, J. 2004. R\&D cooperation and innovation activities of firms: evidence for the German manufacturing industry. Research Policy, vol. 33, no. 2. pp. 209-223.

Burgelman, R.A., Christensen, C., and Wheelwright, S. 2004. Strategic Management of Technology and Innovation. 4th edn. McGraw-Hill/Irwin, New York.

Beukes, J.P., DAwson, N.F., and van ZyL, P.G. 2010. Theoretical and practical aspects of $\mathrm{Cr}(\mathrm{VI})$ in the South African ferrochrome industry. Journal of the Southern African Institute of Mining and Metallurgy, vol. 110 . pp. $743-750$.

Biermann, W., Cromarty, R.D., and Dawson, N.F. 2012. Economic modelling of a ferrochrome furnace. Journal of the Southern African Institute of Mining and Metallurgy, vol. 112. pp. 301-308.

CHo, D. and PyunG-IL, Y. 2000. Influential factors in the choice of technology acquisition mode: an empirical analysis of small and medium size firms in the Korean telecommunication industry. Technovation, vol. 20. pp. 691-704.

CREAMER, M. 2017. Strong outlook for recovering ferrochrome industry Merafe. Polity. http://www.polity.org.za/article/strong-outlook-forrecovering-ferrochrome-industry-merafe-2017-03-08.

CRowson, P. 2001. Mining industry profitability? Resources Policy, vol. 27, no. 1. pp. 33-42.
ForD, D. 1988. Develop your technology strategy. Long Range Planning vol. 21. pp. 85-95.

FowKES, K. 2013. Developments in production costs and competitiveness in ferrochrome. Proceedings of the Metal Bulletin International Ferroalloys Conference. Barcelona, Spain, 10-12 November 2013.. http://www.alloyconsult.com/files/MB_conf_presentation__SA_Sep_2013.pdf

FowKES, K. 2014. Is there a limit to the market share of South African chrome units? Proceedings of the 7th South African Ferroalloys Conference, Johannesburg, South Africa, 4 September 2014. http://www.alloyconsult.com/files/MB_conf_presentation__SA_Sep_2014.pdf

International Ferro Metals (IFM) 2013. Integrated Annual Report 2013. International Ferro Metals, Sydney.

JAIPURIA, S. and MAHAPATRA, S.S. 2014. An improved demand forecasting method to reduce bullwhip effect in supply chains. Expert Systems with Applications, vol. 41. pp. 2395-2408.

JERRETT, D. and Cuddington, J.T. 2008. Broadening the statistical search for metal price super cycles to steel and related metals. Resources Policy, vol. 33, no. 4. pp. 188-195.

KLEYNHANS, E. 2011. Unique challenges of clay binders in a pelletised chromite pre-reduction process - a case study. MSc dissertation, North-West University. http://repository.nwu.ac.za/handle/10394/7370

KUROKAWA, S. 1997. Make-or-buy decisions in R\&D: small technology-based firms in the United States and Japan. Engineering Management, IEEE Transactions, vol. 44. pp. 124-134.

LunDQuisT, G. 1999. Technology and the Agents of Change. Parker, C.O. (ed.). The Market Engineering Press, Parker, co.

MURTHY, Y.R., TRIPATHY, S.K., and KUMAR, C.R. 2011. Chrome ore beneficiation challenges and opportunities - a review. Minerals Engineering, vol. 24. pp. 375-380.

RICHARD, P. 2015. Overview of global chrome market. Proceedings of the 1st INDINOX Stainless Steel Conference, Ahmedabad, India, 25 January 2015. International Chromium Development Association. pp. 1-21.

ROBERTS, M.C. 2009. Duration and characteristics of metal price cycles. Resources Policy, vol. 34, no. 3. pp. 87-102.

SHAFIEE, S. and TopaL, E. 2010. An overview of global gold market and gold price forecasting. Resources Policy, vol. 35, no. 3. pp. 178-189.

Schlorke, K.H. 2011. Technology acquisition modes and product development performance in the electronics industry in South Africa. MEng dissertation, University of Pretoria.

SHERIDAN, J.H. 1997. Managing peaks and valleys. Industry Week, 3 November, pp. 13-20.

SimatuPANG, T. 2006. Study of technology acquisition modes: the choice between making and buying technology. PhD thesis, RMIT Universityy, Melbourne.

TsAI, K. and WANG, J. 2008. External technology acquisition and firm performance: a longitudinal study. Journal of Business Venturing, vol. 23 , no. 1. pp. 91-112.

US Geological SuRvey 2017. Mineral commodity summaries 2017. p. 202. https://doi.org/10.3133/70180197

Vinell, L. 1997. Business cycles and steel markets. Beckmans Bokforlag AB, Stockholm. 